\title{
A vital clue to deciphering bone pathology: MRI bone oedema in rheumatoid arthritis and osteoarthritis
}

F M McQueen

E vidence is mounting that MRI bone oedema is an important finding both in rheumatoid arthritis (RA) and osteoarthritis (OA). It is associated with pain in both conditions ${ }^{12}$ signalling disease activity, and is also a marker of poor prognosis, predicting joint damage and radiographic progression. ${ }^{34}$ While the articular pathology of RA clearly differs from that of OA, the finding of bone oedema informs us about a region of critical importance to both conditions, the subchondral bone. This vital tissue, lying directly below the articular cartilage, has hitherto been inaccessible and consequently rather neglected. Using the window provided by MRI, the subchondral bone has now been shown to be far from an inert framework sitting passively beneath the joint, but rather to be intimately involved in the pathological processes producing joint inflammation and leading to destruction. This review will begin by describing the MRI characteristics of bone oedema and then explore data from clinical and histopathological studies that shed light on its nature and significance in RA and OA.

\section{MRI FEATURES OF BONE-MARROW OEDEMA}

Bone-marrow oedema is the term describing an MRI appearance resulting from replacement of bone-marrow fat by material containing $\mathrm{H}^{+}$ions, in the form of water. ${ }^{5}$ This is usually contained within cells, but in some situations it may be free-for example in regions of intraosseous necrosis or bleeding. Bone oedema is a feature unique to MRI and cannot usually be visualised by radiographic techniques such as $x$ ray or CT scanning (figl). Similarly, it is invisible to ultrasound, which depends on reflection of sound waves from bone and tissue boundaries. Even Doppler ultrasound, which is a useful tool for exploring the vascularised synovium, ${ }^{6}$ cannot detect bone oedema, as it is hidden sonically

Abbreviations: $B M D$, bone mineral density; $B M L$, bone-marrow lesions; DMARD, diseasemodifying antirheumatic drug; $O A$, osteoarthritis; RA, rheumatoid arthritis within the echogenic bone. Bone oedema has particular significance because of the importance of water in biological systems, especially when this is detected at sites such as the subchondral bone where it is not normally found. It implies the presence of cells and potentially, of inflammation, with all its consequences for the bone, the joint and the patient as a whole.

\section{MRI BONE OEDEMA IN RA}

\section{Clinical studies}

MRI bone oedema was first reported in RA at the wrist by Koenig et al in $1986 .^{7}$ It has been described as having a diffuse "feathery" appearance with indistinct margins and is often associated with joint erosions. $^{5}$ It was first recognised as a common lesion in early RA when described in $64 \%$ of a cohort of patients from New Zealand who had wrist MRI scans at the time of diagnosis. ${ }^{1}$ Others have since confirmed its frequency in early disease, including Ostendorf et al who described bone oedema at the forefeet in 7 of 10 patients with normal hand MRI scans, who had only had symptoms for a median of 9 weeks. ${ }^{8}$ McQueen et al examined 15 sites at the wrist in 42 RA patients and used 542 paired observations at 1 year and 407 at 6 years to examine the fate of wrist bones that were not eroded at baseline. ${ }^{49}$ The risk of erosion was increased more than sixfold if bone

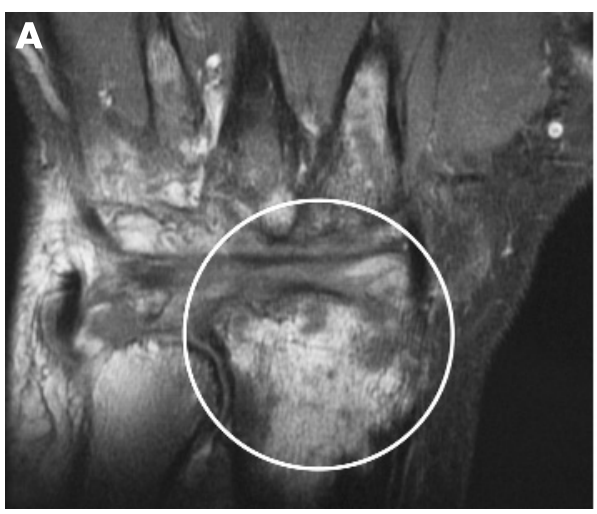

Figure 1 (A) Tlw postcontrast coronal MRI wrist scan of a patient with RA (6-year duration) showing extensive bone oedema involving the distal radius. (B) Matching multidetector CT scan reveals areas of erosion but no bone oedema.

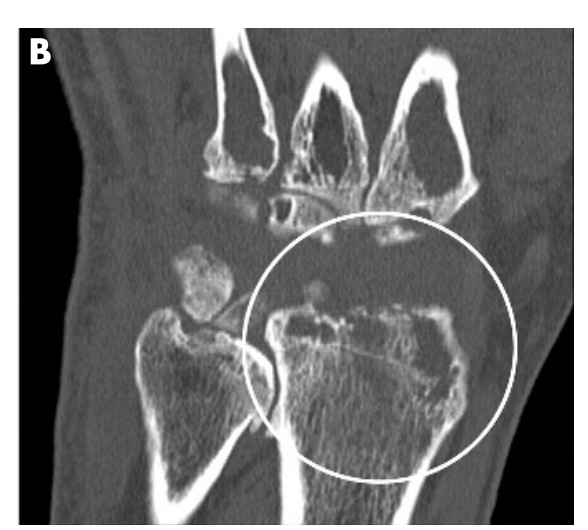

oedema had been detected at that site previously. After 6 years, the bone oedema score at the wrist was the only single baseline MRI variable for the group as a whole to predict the Sharp van der Heijde score $^{10}$ quantifying radiographic damage at both hands and feet. Analysis of these data showed that bone oedema was separately predictive of both the joint space narrowing and erosion components of this score, suggesting an influence not only on subchondral bone but also possibly on cartilage. ${ }^{4}$ In this cohort, baseline bone oedema was also, surprisingly, a predictor of function at 6 years as measured by the SF-36 and was the only separate clinical or MRI feature to achieve this. ${ }^{11}$

Recently, these findings have been confirmed by the largest MRI study of early RA reported to date. Haavardsholm et al followed 84 Norwegian patients over 1 year and found bone oedema and male sex to be the only baseline variables capable of predicting radiographic erosive progression. ${ }^{12}$ Groups from Denmark and Finland have also reported this association with erosion after 1 and 2 years, ${ }^{13-15}$ and recently a Japanese group showed in 80 RA patients that bone oedema was twice as common in those who were antiCCP+ve, suggesting a link to an "aggressive disease" profile. $^{16}$ Moreover, bone oedema scores have consistently been found to correlate with indicators of disease activity including CRP, ESR and pain score. ${ }^{17^{18}}$ High-grade bone oedema has been shown to occur frequently in regions targeted for joint replacement surgery, possibly because of its association with pain and bone destruction. ${ }^{17}$ Scores fall in response to anti-TNF therapy, ${ }^{19}{ }^{20}$ and bone oedema was recently proposed to be part of the "inflammatory lesion" within the rheumatoid joint, which can be measured using a composite MRI score for bone oedema, synovitis and tenosynovitis. $^{20}$ Consistent with this concept, Hodgson et al have now reported findings 
from an MRI study of 25 RA patients where standard $\mathrm{T} 2 \mathrm{~W}$ sequences and dynamic enhanced scans of the MCPs and wrists were obtained pre- and post anti-TNF therapy. ${ }^{21}$ The relative enhancement rate on dynamic scans, which depends on tissue vascularity, was high in regions of bone oedema and fell after anti-TNF therapy, in very much the same way as has been observed in the inflamed synovium. $^{22}$

Thus, bone oedema seems to play a crucial role in RA, straddling the processes of acute disease activity, where it is linked to inflammation and can respond to biological disease-modifying antirheumatic drugs, and structural joint damage, where the evidence is strong that it is a forerunner of radiographic progression and poor outcome. Clearly, there is an urgent need for it to be properly characterised histologically, but to achieve this, the hurdle of obtaining tissue has had to be overcome. Short of plunging a bone-marrow trephine needle into the wrist (which may not be well received), the subchondral bone in patients with early RA remains largely inaccessible. However, material is available from patients undergoing joint replacement, albeit with the caveat that this will represent advanced disease with a component of secondary osteoarthritis likely.

\section{Histopathology and animal models}

In April of this year, Jimenez-Boj et al described a study of 12 joints resected from three patients with advanced RA undergoing joint replacement. MRI scans were obtained preoperatively and attempts were made to align slices with histological sections of the excised bone. ${ }^{23}$ They found that regions of MRI bone oedema corresponded with regions of inflammation, being associated variously with invading pannus, lymphocytic aggregates and increased vascularity. McQueen et al recently published a similar study where bone was obtained from joints of the hands or feet of patients with longstanding RA. ${ }^{17}$ They also described florid bone oedema corresponding with active osteitis and compared this with regions where there was no bone oedema and no histological evidence of inflammation. These studies are exciting as characterisation of the cells involved may be informative as to the underlying immunopathology of RA. Lymphoid aggregates in close association with osteoclasts have been described by others in rheumatoid subchondral bone, 2425 and combined with imaging evidence, this suggests a mechanism for the genesis and progression of erosions. ${ }^{26}$ Data from animal models are also just emerging, and Proulx et al recently described an active inflammatory infiltrate replacing marrow fat, which corresponded with regions of MRI bone oedema, in a TNF-transgenic mouse model. ${ }^{27}$ Neither MRI bone oedema nor histological evidence of osteitis was found in wild-type mice without arthritis. Further studies of this type should allow bone oedema to be investigated in the early phases of arthritis, when human tissue is not usually available.

\section{MRI BONE OEDEMA IN OA Clinical studies}

Given that MRI bone oedema seems to represent such an important lesion in RA, it is slightly disconcerting to discover that it also occurs, possibly even more commonly, in OA where it is also linked to pain and radiographic progression. Most studies have focused on the knee and what are sometimes described as "hemispheric" regions of bone oedema ${ }^{28}$ that have been termed bone-marrow lesions (BML) in recognition of the lack of information about their histology. Felson et al investigated 401 patients with radiographic knee $\mathrm{OA}$, and found BML in $78 \%$ of those with knee pain compared with $30 \%$ of those without, giving an odds ratio of 3.3 for the association. The same authors recently published a longitudinal case-control study over 15 months. This time, subjects were enrolled who did not have knee pain but had existing OA or were at high risk for developing this. ${ }^{29}$ Enlargement of the BML was the end point investigated and was much more common in case knees (where pain developed) than controls with an odds ratio of 3.2.[1.5-6.8] Thus, the evidence is now strong that bone oedema is associated with pain in the setting of knee OA and that there is a dose-effect relationship in that more pain tends to go with larger lesions.

The BMLs of OA are also associated with progressive joint damage. Felson et al demonstrated a strong association between the presence of a BML and ipsilateral radiographic progression during follow-up at 15 and 30 months. ${ }^{3}$ Within the medial knee compartment, this risk was increased more than sixfold in those with medial BMLs. There was also an association between BMLs and malalignment, with for example a high prevalence of lateral lesions in valgus limbs. ${ }^{3}$ These authors concluded that "bone trauma" was the best explanation for the MRI bone oedema lesion with damage and deformity of subchondral bone eventually leading to radiographic change. An association between bone oedema and collagen breakdown products supports this. ${ }^{30}$ Levels of urinary C-terminal crosslinking telopeptide of type II collagen (CTX-II) reflecting collagen degradation were strongly associated with bone-marrow abnormality scores in a cohort of 377 patients. When followed longitudinally, changes in CTX-II correlated with changes in the BML score, indicating that both measures can be viewed as useful biomarkers in this disease. ${ }^{30} \mathrm{~A}$ further clue as to the nature of BMLs in OA comes from Lo et al, who investigated their association with bone mineral density (BMD) at medial and lateral compartments of the knee. They found that medial BMLs tended to occur in knees with higher relative medial tibial bone density, suggesting that local BMD reflects loading and also tying in with evidence from histopathology (see below) that bone oedema in OA is associated with trabecular remodelling and thickening. ${ }^{28}$

\section{Histopathology and animal models}

The studies correlating bone oedema with histopathology in OA have produced mixed results. Lesions described range from bone-marrow necrosis to fibrosis with vascularisation extending into the hyaline cartilage. ${ }^{28}{ }^{31}$ However, a common feature is the replacement of bone-marrow fat with cellular or necrotic tissue which will be sufficient to produce increased signal on T2WFS or STIR MR images. In contrast to the situation in RA, there seems to be more fibrosis than inflammation, and a consistent feature has been thickening and remodelling of trabeculae along with subchondral cyst formation. Tan et al recently described bone oedema in OA finger joints, occurring at entheseal sites such as the insertions of collateral ligaments. ${ }^{32}$ Clearly, various processes are taking place, depending on the site examined as well as disease severity and duration. There is some corroborating evidence from animal models of OA. Lahm et al, evaluated subchondral bone in dogs following an induced fracture. ${ }^{33}$ After 6 months, histomorphometry confirmed that trabecular bone volume was increased in the affected knee, indicating that remodelling had occurred. Another group compared MRI bone oedema with histology of the proximal tibia using the Pond-Nuki canine model.$^{34}$ In these dogs, BMLs corresponded with regions of haematopoietic transformation within the bone marrow associated with intertrabecular fibrosis. However, haematopoiesis at this site is a feature of this particular model and does not occur in man, so animal data cannot always be extrapolated to human disease.

\section{SUMMARY}

In summary, MRI bone oedema is an important finding in RA and OA. Points of similarity and difference are listed in table 1. In RA, evidence from the imaging modality itself (increased signal 
Table 1 Bone oedema in RA and OA

\begin{tabular}{lll}
\hline & RA & OA \\
\hline Feature & & $57-82 \%$ at the knee \\
Frequency & $45-64 \%$ at wrist & Subchondral bone \\
Site & Subchondral bone & hemispheric lesions at the knee \\
Appearance & Diffuse, feathery pattern often associated with erosions \\
Predicts radiographic progression & Yes (Sharp van der Heijde score for erosions and joint \\
& space narrowing) & change) \\
Associated with pain & Yes & Yes \\
Associated with increased BMD & No studies* & Yes \\
Associated with malalignment (knee) & No studies & Yes \\
Correlates with collagen breakdown products (urinary CTX-II) & No studies & Yes \\
Correlates with CRP & Yes & No studies \\
Reduced with anti-TNF therapy & Vascularised inflammatory cellular infiltrate (osteitis) \\
Histology of subchondral necrosis bone & Fibrosis, necrosis, trabecular remodelling \\
\hline
\end{tabular}

*No direct comparisons but unlikely, as periarticular BMD in RA is low. ${ }^{36}$

postcontrast indicating vascularity) and from limited histopathological studies suggests that bone oedema represents an inflammatory cellular infiltrate within the subchondral bone. It certainly behaves as such in response to biological disease-modifying antirheumatic drugs and could be more sensitive than synovitis as a marker of therapeutic response. ${ }^{21}$ It also predicts radiographic erosive progression and could be regarded as the "missing link" between joint inflammation and damage. In OA, bone oedema is similar in being strongly associated with pain but different in that it is probably not primarily an inflammatory lesion. The pain of OA bone oedema could be due to stimulation of the richly innervated periosteum by mediators released from necrotic tissue, to trabecular microfractures or to a pressure effect from abnormal tissue invading regions that should contain fat alone, as occurs in leukaemic infiltration. ${ }^{35}$ Histological studies have revealed fibrosis and trabecular thickening, to the point that bone density can be increased. This would fit with a process of bone remodelling and fibrosis leading on to joint damage with radiographic progression. Clearly, the subchondral bone is not "inert" in OA any more than it is in RA, and while bone oedema may be a different lesion histologically in these conditions, it is a red flag in both for progressive bone damage and potentially an important biomarker for use in clinical trials.

\section{ACKNOWLEDGEMENTS}

The author is indebted to Dr David Perry for assisting with preparation of images used in fig 1 .

Ann Rheum Dis 2007;66:1549-1552.

doi: 10.1136/ard.2007.082875

Correspondence to: F M McQueen, Department of Molecular Medicine and Pathology, Faculty of Medicine and Health Sciences, University of Auckland, Park Rd, Auckland, New Zealand; f.mcqueen@auckland.ac.nz

\section{Accepted 25 September 2007}

Competing interests: None declared.

\section{REFERENCES}

1 McQueen FM, Stewart N, Crabbe J, Robinson E, Yeoman S, Tan PL, et al. Magnetic resonance imaging of the wrist in early rheumatoid arthritis reveals a high prevalence of erosions at four months after symptom onset. Ann Rheum Dis 1998;57:350-6.

2 Felson DT, Chaisson CE, Hill CL, Totterman SM, Gale ME, Skinner KM, et al. The association of bone marrow lesions with pain in knee osteoarthritis [see comment]. Ann Intern Med 2001;134:541-9.

3 Felson DT, McLaughlin S, Goggins J, LaValley MP, Gale ME, Totterman S, et al. Bone marrow edema and its relation to progression of knee osteoarthritis. Ann Intern Med 2003;139:330-6.

4 McQueen FM, Benton N, Perry D, Crabbe J, Robinson E, Yeoman S, et al. Bone edema scored on magnetic resonance imaging scans of the dominant carpus at presentation predicts radiographic joint damage of the hands and feet six years later in patients with rheumatoid arthritis. Arthritis Rheum 2003;48:1814-27.

5 Peterfy CG. MRI of the wrist in early rheumatoid arthritis. Ann Rheum Dis 2004;63:473-7.

6 Szkudlarek M, Court-Payen M, Strandberg C, Klarlund M, Klausen T, Ostergaard M. Power Doppler ultrasonography for assessment of synovitis in the metacarpophalangeal joints of patients with rheumatoid arthritis: a comparison with dynamic magnetic resonance imaging. Arthritis Rheum 2001;44:2018-23.

7 Koenig H, Lucas D, Meissner R. The wrist: a preliminary report on high-resolution MR imaging Radiology 1986; 160:463-7.

8 Ostendorf B, Scherer A, Modder U, Schneider M. Diagnostic value of magnetic resonance imaging of the forefeet in early rheumatoid arthritis when findings on imaging of the metacarpophalangeal joints of the hands remain normal. Arthritis Rheum 2004;50:2094-102.

9 McQueen FM, Stewart N, Crabbe J, Robinson E, Yeoman S, Tan PL, et al. Magnetic resonance imaging of the wrist in early rheumatoid arthritis reveals progression of erosions despite clinical improvement. Ann Rheum Dis 1999;58:156-63.

10 van der Heijde DM, van Riel PL, Nuver-Zwart IH, Gribnau FW, vad de Putte LB. Effects of hydroxychloroquine and sulphasalazine on progression of joint damage in rheumatoid arthritis. Lancet 1989; 1:1036-8.

11 Benton N, Stewart N, Crabbe J, Robinson E, Yeoman S, McQueen FM. MRI of the wrist in early rheumatoid arthritis can be used to predict functional outcome at 6 years. Ann Rheum Dis 2004;63:555-61.

12 Haavardsholm EA, Bøyesen P, Østergaard M, Schilvold A, Kvien TA. MRI-detected bone marrow edema is a predictor of subsequent radiographic progression in early rheumatoid arthritis. Ann Rheum Dis, 2007:66(Suppl II), 94.

13 Lindegaard HM, Vallo J, Horslev-Petersen K, Junker P, Ostergaard M. Low-cost, low-field dedicated extremity magnetic resonance imaging in early rheumatoid arthritis: a 1-year follow-up study. Ann Rheum Dis 2006;65:1208-12.
14 Palosaari K, Vuotila J, Takalo R, Jartti A, Niemela RK, Karjalainen A, et al. Bone oedema predicts erosive progression on wrist MRI in early $\mathrm{RA}-$ a 2 -yr observational MRI and NC scintigraphy study. Rheumatology 2006;45:1542-8.

15 Savnik A, Malmskov H, Thomsen HS, Graff LB, Nielsen H, Danneskiold-Samsoe B, et al. MRI of the wrist and finger joints in inflammatory joint diseases at 1-year interval: MRI features to predict bone erosions. Eur Radiol 2002;12:1203-10.

16 Tamai M, Kawakami A, Uetani M, Takao S, Tanaka F, Nakamura $\mathrm{H}$, et al. The presence of anticyclic citrullinated peptide antibody is associated with magnetic resonance imaging detection of bone marrow oedema in early stage rheumatoid arthritis. Ann Rheum Dis 2007;65:133-4.

17 McQueen FM, Gao A, Østergaard M, King A, Shalley G, Robinson E, et al. High grade MRI bone oedema is common within the surgical field in rheumatoid arthritis patients undergoing joint replacement and is associated with osteitis in subchondral bone. Ann Rheum Dis, 2007;65:doi:10.1136/ard.2007.070326

18 Tamai M, Kawakami A, Takao S, Uetani M, Arima $\mathrm{K}$, Tanaka $\mathrm{F}$, et al. Bone marrow oedema determined by MRI reflects severe disease status in patients with early-stage rheumatoid arthritis. Ann Rheum Dis, 2006;65(Suppl II), 629

19 Quinn MA, Conaghan PG, O'Connor PJ, Karim Z, Greenstein A, Brown A, et al. Very early treatment with infliximab in addition to methotrexate in early, poor-prognosis rheumatoid arthritis reduces magnetic resonance imaging evidence of synovitis and damage, with sustained benefit after infliximab withdrawal: results from a twelve-month randomized, double-blind, placebo-controlled trial. Arthritis Rheum 2005;52:27-35.

20 Haavardsholm E, Østergaard M, Schildvold A Kvien T. MRI findings reflecting inflammation is more responsive than clinical measures of disease activity when monitoring anti-TNF alpha treatment in RA patients. Arthritis Rheum 2006;54(Suppl):S800.

21 Hodgson R, Grainger A, O'Connor P, Barnes T, Connolly S, Moots R. Dynamic contrast enhanced MRI of bone marrow oedema in rheumatoid arthritis. Ann Rheum Dis. In press.

22 Huang J, Stewart N, Crabbe J, Robinson E, McLean L, Yeoman S, et al. A 1-year follow-up study of dynamic magnetic resonance imaging in early rheumatoid arthritis reveals synovitis to be increased in shared epitope-positive patients and predictive of erosions at 1 year. Rheumatology 2000;39:407-16.

23 Jimenez-Boj E, Nöbauer-Huhmann I, HanslikSchnabel F, Dorotka R, Wanivenhaus A Kainberger $F$, et al. Bone erosions and bone marrow edema as defined by magnetic resonance imaging reflect true bone marrow inflammation in rheumatoid arthritis. Arthritis Rheum 2007;56: 111 18-24.

24 Bugatti S, Caporali R, Manzo A, Vitolo B, Pitzalis C, Montecucco C. Involvement of subchondral bone marrow in rheumatoid arthritis: lymphoid neogenesis and in situ relationship to subchondral bone marrow osteoclast recruitment. Arthritis Rheum 2005;52:3448-59. 
25 Watson WC, Tooms RE, Carnesale PG, Dutkowsky JP. A case of germinal center formation by CD45RO T and CD20 B lymphocytes in rheumatoid arthritic subchondral bone: proposal for a two-compartment model of immune-mediated disease with implications for immunotherapeutic strategies. Clin Immunol Immunopathol 1994;73:27-37.

26 McQueen FM, Ostendorf, B. What is MRI bone oedema in rheumatoid arthritis and why does it matter? Arthritis Res Ther 2006;8:222-5.

27 Proulx S, Kwok E, Shealy D, Ritchlin C, Schwarz E. Understanding bone marrow edema in arthritis: 3D-MRI \& histology analyses of TNF-Tg Mice. Arthritis Rheum 2006;54(Suppl):S798-9.

28 Bergman AG, Willen HK, Lindstrand AL, Pettersson HT. Osteoarthritis of the knee: correlation of subchondral MR signal abnormalities with histopathologic and radiographic features. Skeletal Radiol 1994;23:445-8.
29 Felson DT, Niu J, Guermazi A, Roemer F, Aliabadi P, Clancy $M$, et al. Correlation of the development of knee pain with enlarging bone marrow lesions on Magnetic Resonance Imaging Arthritis Rheum 2007;56:2986-92.

30 Garnero P, Peterfy C, Zaim S, Schoenharting M. Bone marrow abnormalities on magnetic resonance imaging are associated with type II collagen degradation in knee osteoarthritis: a three-month longitudinal study. Arthritis Rheum 2005:52:2822-9.

31 Zanetti M, Bruder E, Romero J, Hodler J. Bone marrow edema pattern in osteoarthritic knees: correlation between MR imaging and histologic findings. Radiology 2000;215:835-40.

32 Tan AL, Toumi H, Benjamin M, Grainger AJ, Tanner SF, Emery P, et al. Combined highresolution magentic resonance imaging and histological examination to explore the role of ligaments and tendons in the phenotypic expression of early hand osteoarthritis. Ann Rheum Dis 2007;65:1267-72.

33 Lahm A, Uhl M, Edlich M, Erggelet C, Haberstroh J, Kreuz PC. An experimental canine model for subchondral lesions of the knee joint. Knee 2005; 12:51-5.

34 Pond MJ, Nuki G. Experimentally-induced osteoarthritis in the dog. Ann Rheum Dis 1973;32:387-8

35 Nies BA, Kundel DW, Thomas LB, Freireich EJ. Leukopenia, bone pain, and bone necrosis in patients with acut leukemia: a clinicopathologic complex. Ann Intern Med 1965;62:698-705.

36 Naumann L, Backhaus M, Jonas G, Burmester F. Change in hand bone mineral density in rheumatoid arthritis highly correlates with bone mineral density of spine and femur and depends on disease activity and disease duration. Ann Rheum Dis 2007;66(Suppl II):95

\section{BMJ Clinical Evidence-Call for contributors}

BMJ Clinical Evidence is a continuously updated evidence-based journal available worldwide on the internet which publishes commissioned systematic reviews. BMJ Clinical Evidence needs to recruit new contributors. Contributors are healthcare professionals or epidemiologists with experience in evidence-based medicine, with the ability to write in a concise and structured way and relevant clinical expertise.

Areas for which we are currently seeking contributors:

- Secondary prevention of ischaemic cardiac events

- Acute myocardial infarction

- MRSA (treatment)

- Bacterial conjunctivitis

However, we are always looking for contributors, so do not let this list discourage you.

Being a contributor involves:

- Selecting from a validated, screened search (performed by in-house Information Specialists) valid studies for inclusion.

- Documenting your decisions about which studies to include on an inclusion and exclusion form, which we will publish.

- Writing the text to a highly structured template (about 1500-3000 words), using evidence from the final studies chosen, within 8-10 weeks of receiving the literature search.

- Working with BMJ Clinical Evidence editors to ensure that the final text meets quality and style standards.

- Updating the text every 12 months using any new, sound evidence that becomes available. The BMJ Clinical Evidence in-house team will conduct the searches for contributors; your task is to filter out high quality studies and incorporate them into the existing text.

- To expand the review to include a new question about once every 12 months.

In return, contributors will see their work published in a highly-rewarded peer-reviewed international medical journal. They also receive a small honorarium for their efforts.

If you would like to become a contributor for BMJ Clinical Evidence or require more information about what this involves please send your contact details and a copy of your CV, clearly stating the clinical area you are interested in, to CECommissioning@bmigroup.com.

\section{Call for peer reviewers}

BMJ Clinical Evidence also needs to recruit new peer reviewers specifically with an interest in the clinical areas stated above, and also others related to general practice. Peer reviewers are healthcare professionals or epidemiologists with experience in evidence-based medicine. As a peer reviewer you would be asked for your views on the clinical relevance, validity and accessibility of specific reviews within the journal, and their usefulness to the intended audience (international generalists and healthcare professionals, possibly with limited statistical knowledge). Reviews are usually 1500-3000 words in length and we would ask you to review between 2-5 systematic reviews per year. The peer review process takes place throughout the year, and our turnaround time for each review is 10-14 days. In return peer reviewers receive free access to BMJ Clinical Evidence for 3 months for each review.

If you are interested in becoming a peer reviewer for BMJ Clinical Evidence, please complete the peer review questionnaire at www.clinicalevidence.com/ceweb/contribute/peerreviewer.jsp 